\title{
CONSCIENTIZAÇÃO E IMUNIZAÇÃO ANTIRRÁBICA DOS ALUNOS INGRESSANTES EM 2013 NO CURSO DE MEDICINA VETERINÁRIA NA UNIVERSIDADE FEDERAL DE GOIÁS (UFG), CAMPUS JATAÍ
}

(SENSITIZATION AND ANTI-RABIES IMMUNIZATION OF STUDENTS ENTERING IN 2013 IN THE VETERINARY MEDICINE COURSE IN UNIVERSIDADE FEDERAL DE GOIÁS (UFG), JATAÍ CAMPUS)

\section{M. ANDRASCHKO ${ }^{1}$, H. C. M. PIRES ${ }^{1}$, E. D. F. CAMILO ${ }^{1}$, D. A. AZEVEDO ${ }^{2}$, D. B. SOUSA ${ }^{3}$, R. B. MEIRELLES-BARTOLI ${ }^{3 *}$}

A profilaxia pré-exposição da raiva deve ser indicada para pessoas com risco de exposição permanente ao vírus rábico. São três doses, nos dias 0,7 e 28 , e controle sorológico a partir do $14^{\circ}$ dia após a última dose. Uma dose reforço deve ser aplicada se o título for menor que $0,5 \mathrm{UI} / \mathrm{mL}$, repetindo-se a avaliação sorológica. O processo educativo tem como ferramentas básicas a participação da sociedade e a comunicação social, devendo ser necessariamente envolvidos os serviços interinstitucionais, intersetoriais e multidisciplinares. O presente trabalho objetivou conscientizar os novos alunos do curso de Medicina Veterinária da UFG, Campus Jataí, sobre a importância desta zoonose, tanto no caráter profissional quanto em saúde pública, e garantir que a profilaxia préexposição fosse feita já no início do curso protegendo-os para as aulas práticas e estágios. No dia da matrícula foi entregue aos 60 ingressantes um material educativo contendo informações gerais sobre a importância da raiva e sua profilaxia. Também foi agendada uma consulta médica para cada aluno na Unidade Básica de Saúde Central, devido a necessidade de prescrição médica para aplicação desta vacina. Durante a execução destas ações, foi possível notar que existe certo desconhecimento sobre a importância de que profissionais que atuam diretamente com animais tenham que se vacinar contra a raiva. O esquema vacinal foi realizado em $100 \%$ dos ingressantes. Sendo que, 83,4\% (50/60) compareceram em suas consultas agendadas para o recebimento da $1^{\text {a }}$ dose vacinal, e $16,6 \%(10 / 60)$ tiveram que ser reagendados para outra data. Após contato por telefone, a principal justificativa da falta foi o esquecimento. A conscientização sobre zoonoses do Médico Veterinário deve começar no início da formação acadêmica, assim como a imunização. Portanto a instituição de um programa educativo desde o início da graduação é de extrema relevância para proteção da saúde ao longo da carreira profissional.

\footnotetext{
${ }^{1}$ Residentes do Programa de Residência Multidisciplinar em Saúde - Medicina Veterinária da Universidade Federal de Goiás - Campus Jataí.

${ }^{2}$ Aluno do Curso de Medicina Veterinária da Universidade Federal de Goiás, Campus Jataí.

${ }^{3}$ Docentes do Curso de Medicina Veterinária da Universidade Federal de Goiás/Campus Jataí, Unidade Jatobá, Laboratório de Sanidade Animal. ${ }^{3 *}$ E-mail: raphaellabrasil@ hotmail.com
} 